\title{
Reversal of the hypothalamo-pituitary-adrenal response to oestrogens around puberty
}

\author{
Obaro Evuarherhe, James Leggett, Eleanor Waite, Yvonne Kershaw and Stafford Lightman \\ Henry Wellcome Laboratories for Integrative Neuroscience and Endocrinology, Dorothy Hodgkin Building, Bristol BS1 3NY, UK \\ (Correspondence should be addressed to O Evuarherhe; Email: obaro.evuarherhe@bristol.ac.uk)
}

\begin{abstract}
The neuroendocrine gender dimorphism that begins during perinatal development is completed during puberty. We have previously described how the perinatal gonadal steroids programme hypothalamic-pituitary-adrenal (HPA) activity in adulthood and we now assess the role of peripubertal ovarian hormones. Prepubertal females were treated subcutaneously with either cholesterol or $17 \beta$-oestradiol and their pituitary-adrenal activity was assessed 5 days later. Oestradiol suppressed the ACTH and corticosterone responses to restraint stress in the prepubertal female. Furthermore, groups of female rats were ovariectomised (OVX) either before or after puberty and adult animals were subsequently treated with subcutaneous implants containing either $17 \beta$-oestradiol
\end{abstract}

or cholesterol. Corticosterone pulsatility was assessed using an automated blood sampling system to collect blood from freely moving animals at $10 \mathrm{~min}$ intervals over $24 \mathrm{~h}$. Oestradiol administered to adults that had been OVX either pre- or postpubertally displayed a significantly higher mean corticosterone level as well as increased pulse frequency and pulse amplitude compared with cholesterol treated controls. These data demonstrate a reversal in the effect of oestrogens on HPA axis activity over the time of puberty with inhibitory effects prepubertally and stimulatory actions after puberty and imply an ovarian steroid-independent mechanism of pubertal maturation of HPA sensitivity to oestrogens.

Journal of Endocrinology (2009) 202, 279-285

\section{Introduction}

The organisational role of perinatal gonadal steroids on reproductive behaviour in adulthood was originally demonstrated in the 1950s. Phoenix et al. (1959) showed that the exposure of pregnant dams to testosterone resulted in female offspring displaying masculine behaviour in adulthood. Masculinised female rats have increased body weight (Swanson \& van der 1963), failed to display lordosis during sexual activity and are permanently sterile (Gerall \& Kenney 1970, McDonald \& Doughty 1972). On the basis of this research, along with the evidence demonstrating susceptibility of the hypothalamic-pituitary-adrenal (HPA) axis to neonatal programming (Schapiro 1965, Levine \& Mullins 1967, Sapolsky \& Meaney 1986, Shanks et al. 2000), we have recently shown that perinatal exposure to androgens can permanently affect the HPA axis phenotype in the adult female rat (Seale et al. 2005). Another critical period during which gonadal steroids can activate numerous adult-specific physiological and neurobehavioural traits is puberty. In fact, the activational effects of perinatal gonadal steroid exposure on reproductive behaviour only manifest after pubertal development suggesting that the neuroendocrine gender dimorphism that begins during perinatal development is completed during puberty (Romeo 2003). The pubertal maturation of the hypothalamo-pituitary-gonadal (HPG) axis ultimately results in stimulation of gonadal steroid production and release, which in turn govern numerous secondary sexually dimorphic processes and characteristics. Puberty in female rats is commonly regarded as the period during which vaginal opening and the initial oestrus phase occurs (Azooz et al. 2001). This is followed by the early and late phases of proestrus during which the uteri become noticeably ballooned. It is during this phase that animals begin to display open vaginae (between days 32 and 38; Azooz et al. 2001). The rate limiting factor for the onset of oestrus cyclicity in female rats is the maturation of the ova alongside a dramatic increase in pulsatile GnRH secretion from the hypothalamus (Gore et al. 1996) occurring between days 43 and 47 in females (Sisk et al. 2001).

There is evidence of a pubertal maturation of the HPA axis in female rats (Romeo et al. 2004). Specifically, it was shown that prepubertal rats take longer than adults to terminate an endocrine response to an acute stressor suggesting that the negative-feedback mechanisms regulating the HPA axis undergo a maturational process during puberty. Whether or not the pubertal maturation of the HPA axis is dependent on the rise in gonadal steroids following the rise in frequency and amplitude of $\mathrm{GnRH}$ release or is more related to other maturational processes at the central level independent of gonadal steroids is not known. 
Oestradiol acts via the nuclear oestrogen receptor (ER) isoforms $\alpha$ and $\beta$ (listed as Esr1 and Esr2 in the MGl database), which serve as transcription factors upon activation by oestrogens. There is a paucity of research into ER levels before, during and after puberty in female rats. Studies comparing ER immunoreactivity in various forebrain regions in prepubertal and adult female guinea pigs found no age difference in ER immunostaining in the paraventricular nucleus (PVN) or the amygdala (Olster 1994). This suggests that in rodents, these regions of the brain known to govern HPA activity in adulthood may be capable of responding to oestrogen before puberty; thus the rise in gonadal steroids over puberty may be crucial for the activation of a selection of female neuroendocrine and behavioural traits.

The aim of the present study was to investigate whether HPA activity responded to exogenous oestrogen in prepubertal females and whether ovarian activity during puberty had an organisational effect on the adult HPA axis.

\section{Materials and Methods}

\section{Animals}

Female Sprague-Dawley rats (Harlan, Oxfordshire, UK) were group housed and maintained under $14 \mathrm{~h}$ light: $10 \mathrm{~h}$ darkness cycle (lights on at $0500-1900 \mathrm{~h}$ ) with access to food and water ad libitum and room temperature was maintained between 19 and $23{ }^{\circ} \mathrm{C}$. For post-surgery, all animals were housed under the same conditions. All housing conditions and surgical procedures were carried out in accordance with the animal (Scientific Procedures) Act 1986.

\section{Experimental design}

Two groups of studies were performed. The first group of studies (Study 1) investigated the effect of adult physiological levels of oestradiol on the pituitary-adrenal response to restraint stress in prepubertal females. Owing to their small size, rapid growth and smaller circulating blood volumes, prepubertal animals could not be connected to our automated blood sampling system. Since blood samples could only be obtained following decapitation, this study was designed to minimise the number of necessary blood samples. Study 2 investigated the importance of peripubertal oestrogens on corticosterone secretory profiles in the subsequent adult females and their responses to $17 \beta$-oestradiol.

\section{Study 1}

Animals arrived at 21 days of age. The following day, female rats were anaesthetised using 5\% isoflurane gas (administered with oxygen and nitrogen into an enclosed chamber. Animals were maintained under anaesthesia with 1.5-2\% isoflurane gas delivered through a facemask) and implanted with a subcutaneous silastic implant (length: $0.5 \mathrm{~cm}$, inner diameter: $1.57 \mathrm{~mm}$, outer diameter: $3.18 \mathrm{~mm}$ ) containing either
$17 \beta$-oestradiol (Sigma) or cholesterol (Sigma) a day later. This treatment has been previously shown to deliver adult physiological levels of oestrogen (Seale et al. 2004b). Animals were then left undisturbed until 5 days later (Day 27) when animals were rapidly decapitated either before or after $30 \mathrm{~min}$ of restraint stress. The stressed group of animals were restrained in clear plastic cylindrical restrainers $(10 \times 4 \mathrm{~cm})$ for $30 \mathrm{~min}$ before rapid decapitation. Unstressed animals were killed within $30 \mathrm{~s}$ after entering the holding room. Trunk blood was collected in EDTA/Trasylol lined tubes over wet ice and spun down at $3578 \mathrm{~g}$ in a refrigerated $\left(4^{\circ} \mathrm{C}\right)$ centrifuge for $15 \mathrm{~min}$. Plasma was then aliquoted and stored at $-20^{\circ} \mathrm{C}$ until the corticosterone radioimmunoassays and ACTH IRMAs.

\section{Study 2}

Prepubertal (28 days) female Sprague-Dawley rats (Harlan) were anaesthetised using 5\% isoflurane gas (administered with oxygen and nitrogen into an enclosed chamber. Animals were maintained under anaesthesia with $1 \cdot 5-2 \%$ isoflurane gas delivered through a facemask) and either bilaterally ovariectomised (OVX) or sham-OVX (SHOVX). Animals were then returned to their home cages. At 11 weeks of age (200$300 \mathrm{~g})$, all rats were anaesthetised using diazepam $(2.6 \mathrm{mg} / \mathrm{kg}$, Phoenix Pharmaceuticals, Gloucester, UK) administered intraperitoneally and hypnorm $(0 \cdot 32 \mathrm{mg} / \mathrm{kg}$ fentanyl citrate and $10 \mathrm{mg} / \mathrm{kg}$ fluanisone, Janssen Pharmaceuticals, Wantage, UK) administered intramuscularly. Half of the animals OVX before puberty received subcutaneous silastic implant (length $0.5 \mathrm{~cm}$, inner diameter $1.57 \mathrm{~mm}$, outer diameter $3.18 \mathrm{~mm}$ ) containing crystalline $17 \beta$-oestradiol (Sigma). The other half was implanted subcutaneously with a silastic implant containing crystalline cholesterol (Sigma). Animals SHOVX before puberty were bilaterally OVX and received subcutaneous implants containing either $17 \beta$-oestradiol or cholesterol. To allow for connection to an automated sampling system, a silastic-tipped polythene cannula (inner diameter $0.58 \mathrm{~mm}$, Portex, Hythe, UK) filled with heparinised saline $(10 \mathrm{U} / \mathrm{ml}$ heparin; CP Pharmaceuticals, Wrexham, UK) was inserted in to the right jugular vein of each rat. The cannula was exteriorised at the crown of the rat's head and secured by a spring attached to a $360^{\circ}$ mechanical swivel. The cannula was then connected to an automated blood-sampling system (Windle et al. 1998a). Sampling began 5 days after cannulation surgery at $0700 \mathrm{~h}$. Blood samples were collected from each rat every $10 \mathrm{~min}$ over a $24 \mathrm{~h}$ period under basal conditions. Samples were then spun down at $3578 \mathrm{~g}$ in a refrigerated $\left(4^{\circ} \mathrm{C}\right)$ centrifuge for $15 \mathrm{~min}$. Plasma was then aliquoted and stored at $-20{ }^{\circ} \mathrm{C}$ until the corticosterone RIA. Animals were weighed on a weekly basis from prepubertal surgery until adulthood.

\section{Corticosterone assay}

In study $1,10 \mu \mathrm{l}$ plasma from trunk blood was diluted in $500 \mu \mathrm{l}$ citrate buffer ( $\mathrm{pH} 3 \cdot 0$ ). In study 2, the sampling procedure produced 169 blood samples per animal. During 
sampling, each blood sample $(37 \cdot 7 \mu \mathrm{l})$ was diluted 1:5 heparinised saline. $20 \mu \mathrm{l}$ of each blood sample was further diluted into $80 \mu \mathrm{l}$ citrate buffer $(\mathrm{pH} 3 \cdot 0)$. Samples were processed in triplicate (experiment 1) or duplicate (experiment 2) and incubated overnight at $4{ }^{\circ} \mathrm{C}$ with $50 \mu \mathrm{l}\left[{ }^{125} \mathrm{I}\right]$ corticosterone tracer (ICN Flow, Oxford Bio Innovation DSL Ltd, Oxford, UK) and $50 \mu \mathrm{l}$ rabbit anti-rat corticosterone primary antibody (kindly donated by G Makara, Hungary). On day 2, a charcoal/dextran solution was added to all samples that were then spun refrigerated at $3578 \mathrm{~g}$ for $15 \mathrm{~min}$, aspirated and counted on a gamma counter for $5 \mathrm{~min}$. Plasma corticosterone concentrations were calculated by comparison against calibrated standards run in parallel with unknown samples. The intra- and inter-assay coefficients of variation were $12 \cdot 4$ and $16 \cdot 0 \%$ respectively.

\section{ACTH assay}

Levels of ACTH in the trunk blood were quantitatively deduced using an ACTH IRMA kit (DiaSorin, MN, USA). Totally $200 \mu \mathrm{l}$ plasma was incubated at room temperature for $20 \mathrm{~h}( \pm 2)$ in polypropylene tubes with $50 \mu \mathrm{ACTH}$ IRMA tracer (consisting of goat anti-ACTH, ${ }^{125}$ I labelled-mouse monoclonal anti-ACTH and sodium azide), and one ACTH IRMA bead coated with polyclonal mouse anti-goat antibody. Following the incubation, the unbound fraction was aspirated and the antibody-coated bead was washed vigorously three times with an ACTH IRMA wash solution containing a buffered surfactant. Following the final wash, the remaining wash solution was aspirated and the tubes containing the antibody-coated beads were counted on a gamma counter for a minute.

\section{Statistical analysis}

For Study 1, two-way ANOVA followed by post-hoc tests (Bonferroni) were performed on corticosterone and ACTH data to observe the effects of stress and steroid treatment on stress hormone levels. For Study 2, corticosterone data are presented as group mean area-under-curve, indicative of overall plasma corticosterone secretion over a $24 \mathrm{~h}$ period. The frequency and amplitude of corticosterone pulses over this time period were analysed using Pulsar pulse-analysis software (Merriam \& Wachter 1982, Windle et al. 1998b). Two-way ANOVA and post-hoc Bonferroni tests were used to detect the effects of prepubertal versus adult OVX as well as the effects of oestradiol replacement within groups.

\section{Results}

\section{Study 1}

Prepubertal female rats treated with subcutaneous silastic implants containing crystalline cholesterol displayed a significantly higher corticosterone response to a $30 \mathrm{~min}$ restraint stress compared with females treated with oestradiol implants $(P<0 \cdot 05)$. There was no significant difference in corticosterone levels in both unstressed groups of prepubertal females (Fig. 1A). There was no significant difference in basal ACTH levels between oestradiol and cholesterol treated prepubertal females (Fig. 1B). Following $30 \mathrm{~min}$ of acute restraint stress, prepubertal female rats treated with subcutaneous silastic implants containing crystalline oestradiol displayed a significantly lower ACTH response compared with cholesterol treated females $(P<0 \cdot 001)$.

\section{Study 2}

Animals were weighed on a weekly basis from prepubertal surgery through to adult cannulation surgery. Figure 2 shows the weekly weight gain from puberty to adulthood in animals OVX or SHOVX before puberty. Animals OVX before puberty were significantly heavier than SHOVX animals
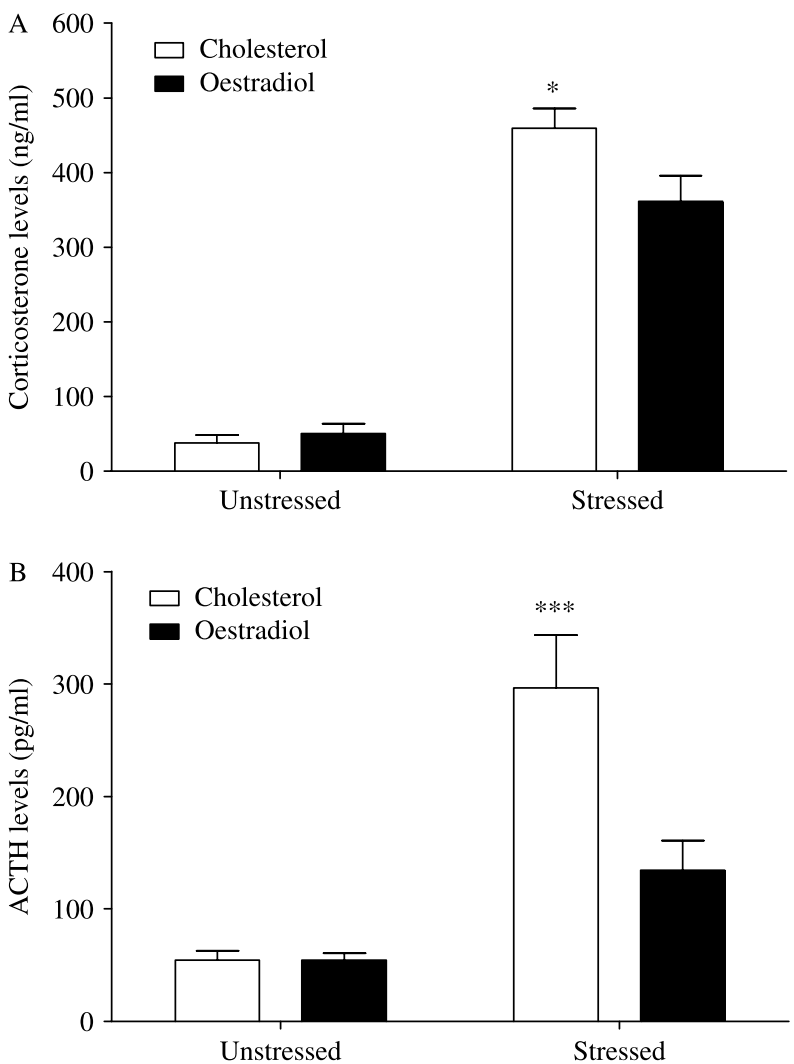

Figure 1 Corticosterone and $\mathrm{ACTH}$ response to restraint stress in prepubertal female rats. Data presented as mean corticosterone $(\mathrm{ng} / \mathrm{ml}) / \mathrm{ACTH}(\mathrm{pg} / \mathrm{ml})$ levels \pm s.E.M. $(n=7-8)$. Statistical analyses; corticosterone: two-way ANOVA: effect of oestradiol treatment: $F(1,27)=3 \cdot 22, P=0 \cdot 0838$; interaction between oestradiol treatment and stress $F(1,27)=5 \cdot 38, P<0 \cdot 05$. * Significant difference from oestradiol treated prepubertal females $(P<0 \cdot 05$, Post-hoc Bonferroni test). ACTH: effect of oestradiol treatment: $F(1,28)=8 \cdot 72$, $P<0 \cdot 05$; interaction between oestradiol treatment and stress $F(1,28)=8 \cdot 76, P<0 \cdot 05 . *$ Significantly different from restrained, oestradiol treated females $P<0 \cdot 001$. 


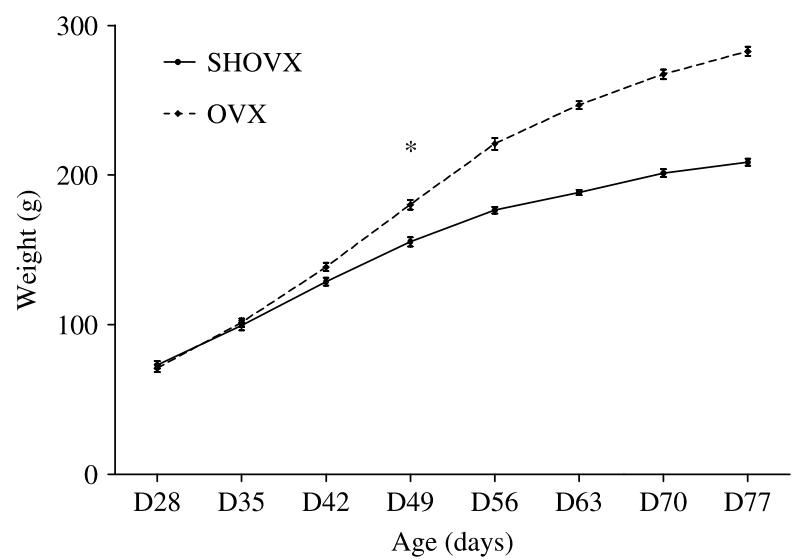

Figure 2 Effect of prepubertal OVX on weekly weight gain until adulthood. Data expressed as weight (g) \pm S.E.M. from day 28 to day $77(n=8)$. Two-way ANOVA revealed OVX females were significantly heavier than SHOVX animals from day 49 until adulthood. Statistical analysis: effect of prepubertal OVX: $F(1,98)=174 \cdot 27$, $P<0 \cdot 0001$. Post-hoc (Bonferroni) analysis revealed that difference in weight between OVX and SHOVX animals becomes statistically significant on day 49 and stays significant $(P<0 \cdot 001)$ from day 56 onwards.

from day 49 until adulthood (Fig. 3). There was a significant effect of oestradiol replacement on area-under-curve $(P<0 \cdot 01)$, pulse frequency $(P<0 \cdot 01)$ and pulse amplitude $(P<0 \cdot 05)$ in all groups of animals with no significant interaction between oestradiol replacement and age of OVX suggesting that oestradiol affects basal corticosterone levels as well as pulse amplitude and frequency independent of age of OVX (Fig. 4).

\section{Discussion}

Previous studies have demonstrated an enhancing effect of oestradiol on HPA axis activity in rodents during different phases of the oestrus cycle (Viau \& Meaney 1991, Atkinson \& Waddell 1997). Other studies have shown that following OVX, treatment with a subcutaneous implant containing $17 \beta$-oestradiol, results in significant enhancement of basal and stress-induced HPA activity (Seale et al. 2004b). In the current group of studies, we investigated whether there was an organisational effect of puberty on HPA activity and whether this was due to the secretion of ovarian hormones.

In prepubertal female rats, s.c. implantation of oestradiol had no effect on basal HPA activity but markedly reduced the ACTH and corticosterone responses to restraint stress. This is a fascinating finding as all previous reports in adult animals show a stimulatory effect of oestrogen on HPA activity (Yukhananov \& Handa 1996, Rachman et al. 1998, Viau \& Meaney 2004, Lund et al. 2006, Handa et al. 2009, Weiser \& Handa 2009). Although there are data suggesting that there is little change in ER prevalence in HPA relevant areas of the CNS over puberty in the guinea pig (Olster 1994), no similar studies have been performed in the prepubertal rat.
Unfortunately, the small plasma volumes of these prepubertal animals prevented us from doing any more detailed studies on basal patterns of HPA activity.

In adult animals, we were able to use our automated-blood sampling system in freely moving animals and were able to
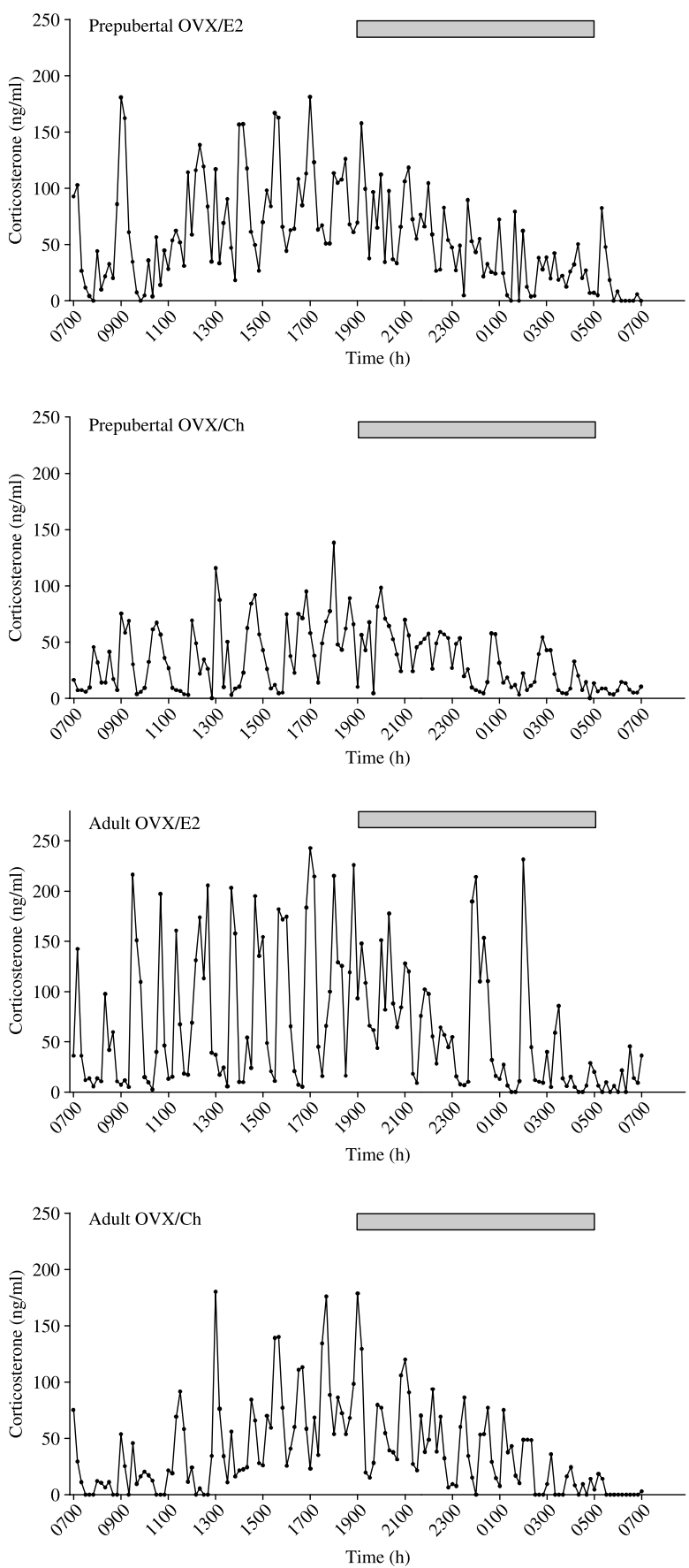

Figure 3 Example profiles. Example $24 \mathrm{~h}$ profiles of corticosterone concentrations in single rats from each treatment group. Animals were maintained on a $14 \mathrm{~h}$ light:10 $\mathrm{h}$ darkness regimen; the dark phase of the cycle is shown by the filled bar. 

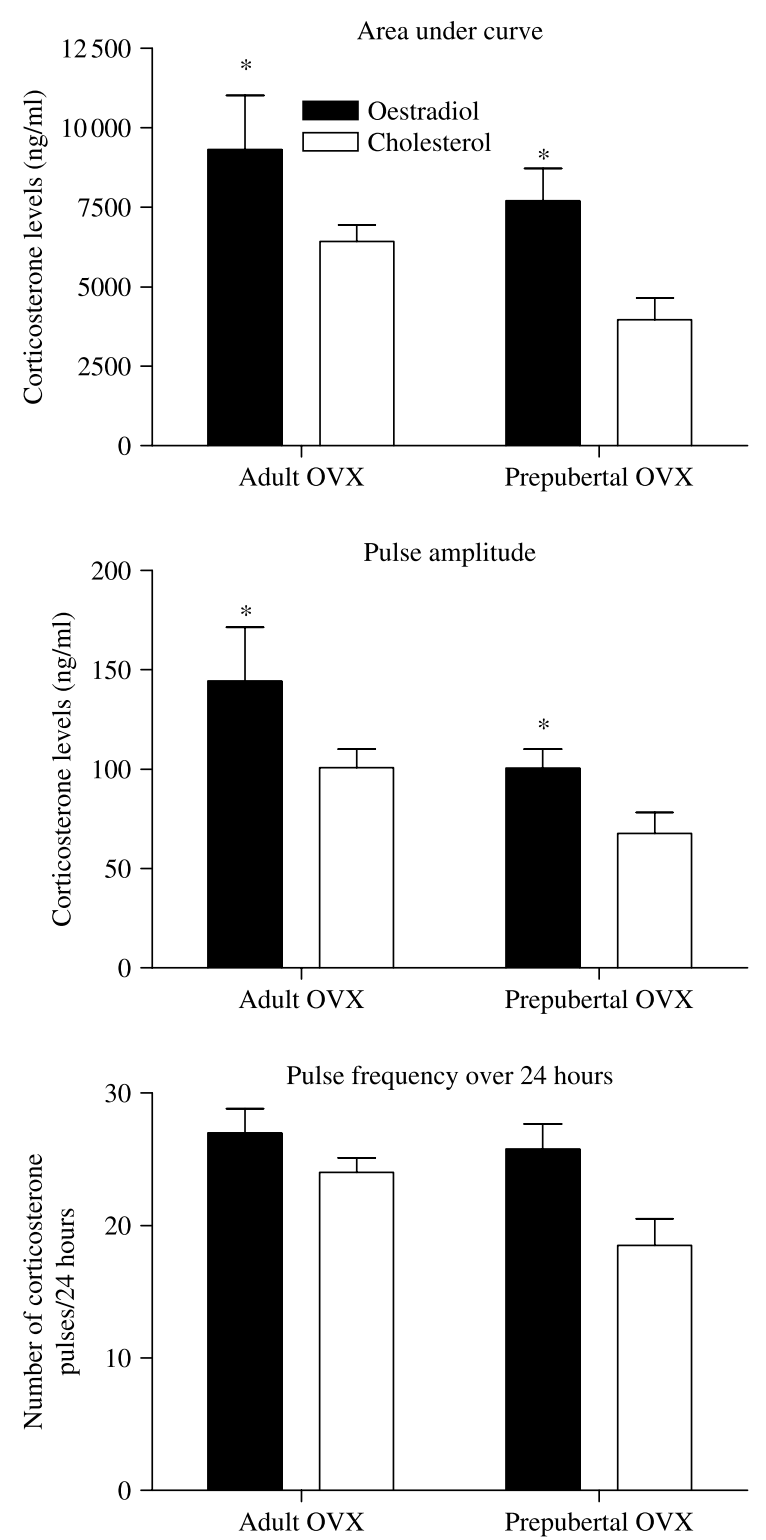

Figure 4 Corticosterone pulse parameters over $24 \mathrm{~h}$ of sampling. Data presented as average corticosterone (area-under-curve and pulse frequency $-\mathrm{ng} / \mathrm{ml}$ ) or average number of corticosterone pulses calculated by PULSAR algorhythm over the $24 \mathrm{~h}$ sampling period. Statistical analyses: area-under-curve; effect of oestradiol replacement: $F(1,12)=9 \cdot 50, P<0 \cdot 01$; effect of age of OVX: $F(1,12)=3 \cdot 6$ (NS). Pulse amplitude: effect of oestradiol replacement; $F(1,12)=5 \cdot 78, P<0 \cdot 05$; effect of age of OVX: $F(1,12)=5 \cdot 83$, $P<0 \cdot 05$. Pulse frequency: effect of oestradiol replacement; $F(1,13)=8 \cdot 18, P=0 \cdot 01$; effect of age of OVX: $F(1,13)=3 \cdot 55$, (NS). *Significantly higher than prepubertal OVX/cholesterol treated group, Bonferroni's post-hoc analysis.

analyse pulsatile corticosterone secretion using a PULSAR algorithm. Oestradiol significantly enhanced basal HPA activity in adult animals that were OVX prepubertally. Similarly, in animals that were SHOVX before the onset of puberty (28 days), oestradiol also significantly enhanced corticosterone release as well as pulse amplitude compared with animals OVX in adulthood and subsequently treated with subcutaneous implants containing crystalline cholesterol. There was no significant effect of the age of OVX on overall corticosterone secretion over $24 \mathrm{~h}$, but there was a consistent stimulatory effect of oestradiol-replacement on all parameters of pulsatile corticosterone secretion. These data are in keeping with studies we have previously carried out in adult female rats showing that OVX resulted in reduced basal - and stress induced - HPA activity and that these responses could be restored by subsequent oestradiol replacement (Seale et al. 2004b). It is clear, therefore, that our current and published data confirm that oestradiol increases both basal and stress induced ACTH and corticosterone secretion in OVX adult animals and that this occurs whether the ovariectomy has taken place prior to puberty or post-puberty.

Since in the current studies we have shown that prior to puberty, oestradiol has an inhibitory effect on HPA activity, whereas after puberty it has a stimulatory effect on HPA activity, there is clearly a maturational change taking place in the pathways governing HPA activity over the period of puberty. Interestingly, this maturational change does not appear to be dependent on ovarian steroids, since even if ovariectomy is performed before puberty, the subsequent adult animal still shows a stimulatory response to oestrogens.

There is evidence that catecholaminergic input to the PVN is involved in the modulation of the HPA axis (Plotsky et al. 1989). The $\alpha_{1}$ adrenoreceptor is present within the PVN and is crucial in the stimulatory effects of noradrenaline on the HPA axis (Kiss \& Aguilera 1992); A recent study by Viau \& Meaney (2004) demonstrated that the stimulatory effect of oestrogens on the adult HPA axis is in part mediated through noradrenergic neurotransmission. It was shown that the stimulatory effects of oestrogen on the HPA axis may be directly due to binding of oestrogen to ERs present in CRF containing neurones in the PVN but are also in part dependent on $\alpha_{1}$ adrenoreceptors. The $\alpha_{1}$ agonist, phenylephrine significantly enhanced the stimulatory effects of endogenous oestrogen on ACTH levels, while the $\alpha_{1}$ antagonist, prazosin significantly suppressed the oestrogeninduced increase in median eminence vasopressin, but not CRF (Viau \& Meaney 2004). Hence, it appears noradrenergic neurotransmission within the hypothalamus may serve as an indirect mechanism via which oestrogen can affect the HPA axis at the hypothalamic level. No such studies have been done in prepubertal females. However, a review by Moguilevsky \& Wuttke (2001) discusses evidence showing that catecholaminergic effects on the HPG axis display qualitative changes over the pubertal period. First, GABAergic systems have a stimulatory effect before puberty, which becomes inhibitory by adulthood. Furthermore, blocking catecholamine synthesis using $\alpha$-methyl- $p$-tyrosine stimulates LH secretion in early puberty, but inhibits GnRH-LH secretion in late puberty and in adulthood (Moguilevsky \& Wuttke 2001). It does appear, therefore, that developmental 
changes in the activity of neurotransmitters, which modulate the influence of oestrogen on the neuroendocrine system do occur over puberty and these may represent the mechanisms through which these animals develop their adult stimulatory HPA response to physiological levels of oestradiol.

Oestrogen may also enhance the adult female HPA axis by affecting corticosteroid receptor-dependent negative feedback. Oestrogen has been shown to reduce glucocorticoid receptor (GR) mRNA expression in the hypothalamus (Seale et al. 2004a,b) and hippocampus (Patchev et al. 1995, Patchev \& Almeida 1996). This serves as a potential mechanism through which oestrogen might reduce the negative feedback influence on the HPA axis, thus enhancing adrenocortical secretion. Romeo et al. (2004) showed that prepubertal female rats take longer to terminate a corticosterone response to restraint stress compared with adults. Taken together, evidence suggests a pubertal maturation of the negative feedback regulation of the HPA axis in females. However, we have no information regarding the possible effects of oestrogen on hippocampal GR levels in prepubertal females.

Our data suggests that there are two critical times for the organisational programming of an adult HPA response to physiological levels of oestrogen. First, there is the neonatal period during which it appears that exposure to sex steroids can programme adult HPA activity (Schapiro 1965, Levine \& Mullins 1967, Patchev et al. 1995, Romeo et al. 2004, Seale et al. 2005) and also puberty during which time a non-sex steroid-dependent maturational process takes place allowing the development of a stimulatory effect of oestrogens on HPA activity.

\section{Declaration of interest}

There is no conflict of interest that could be perceived as prejudicing the impartiality of the research reported.

\section{Funding}

This work was supported by the Neuroendocrinology Charitable Trust (Grant number: RJ4534).

\section{References}

Atkinson HC \& Waddell BJ 1997 Circadian variation in basal plasma corticosterone and adrenocorticotropin in the rat: sexual dimorphism and changes across the estrous cycle. Endocrinology 138 3842-3848.

Azooz OG, Farthing MJ, Savage MO \& Ballinger AB 2001 Delayed puberty and response to testosterone in a rat model of colitis. American Journal of Physiology. Regulatory, Integrative and Comparative Physiology 281 R1483-R1491.

Gerall AA \& Kenney AM 1970 Neonatally androgenized females' responsiveness to estrogen and progesterone. Endocrinology 87 560-566.

Gore AC, Wu TJ, Rosenberg JJ \& Roberts JL 1996 Gonadotropin-releasing hormone and NMDA receptor gene expression and colocalization change during puberty in female rats. Journal of Neuroscience 16 5281-5289.
Handa RJ, Weiser MJ \& Zuloaga DG 2009 A role for the androgen metabolite, 5alpha-androstan- 3beta,17beta diol (3beta-Diol), in modulating estrogen receptor beta mediated regulation of hormonal stress reactivity. Journal of Neuroendocrinology 21 351-358.

Kiss A \& Aguilera G 1992 Participation of alpha 1-adrenergic receptors in the secretion of hypothalamic corticotropin-releasing hormone during stress. Neuroendocrinology 56 153-160.

Levine S \& Mullins R 1967 Neonatal androgen or estrogen treatment and the adrenal cortica response to stress in adult rats. Endocrinology 80 1177-1179.

Lund TD, Hinds LR \& Handa RJ 2006 The androgen 5alphadihydrotestosterone and its metabolite 5alpha-androstan-3beta, 17beta-diol inhibit the hypothalamo-pituitary-adrenal response to stress by acting through estrogen receptor beta-expressing neurons in the hypothalamus. Journal of Neuroscience 26 1448-1456.

McDonald PG \& Doughty C 1972 Comparison of the effect of neonatal administration of testosterone and dihydrotestosterone in the female rat. Journal of Reproduction and Fertility 30 55-62.

Merriam GR \& Wachter KW 1982 Algorithms for the study of episodic hormone secretion. American Journal of Physiology 243 E310-E318.

Moguilevsky JA \& Wuttke W 2001 Changes in the control of gonadotrophin secretion by neurotransmitters during sexual development in rats. Experimental and Clinical Endocrinology and Diabetes 109 188-195.

Olster DH 1994 Hypothalamic estrogen receptor-immunoreactivity in prepubertal vs adult female guinea pigs. Journal of Neuroendocrinology 6 617-625.

Patchev VK \& Almeida OF 1996 Gonadal steroids exert facilitating and "buffering" effects on glucocorticoid-mediated transcriptional regulation of corticotropin-releasing hormone and corticosteroid receptor genes in rat brain. Journal of Neuroscience 16 7077-7084.

Patchev VK, Hayashi S, Orikasa C \& Almeida OF 1995 Implications of estrogen-dependent brain organization for gender differences in hypothalamo-pituitary-adrenal regulation. FASEB Journal 9 419-423.

Phoenix CH, Goy RW, Gerall AA \& Young WC 1959 Organizing action of prenatally administered testosterone propionate on the tissues mediating mating behavior in the female guinea pig. Endocrinology 65 369-382.

Plotsky PM, Cunningham ET Jr \& Widmaier EP 1989 Catecholaminergic modulation of corticotropin-releasing factor and adrenocorticotropin secretion. Endocrine Reviews 10 437-458.

Rachman IM, Unnerstall JR, Pfaff DW \& Cohen RS 1998 Estrogen alters behavior and forebrain c-fos expression in ovariectomized rats subjected to the forced swim test. PNAS 95 13941-13946.

Romeo RD 2003 Puberty: a period of both organizational and activational effects of steroid hormones on neurobehavioural development. Journal of Neuroendocrinology 15 1185-1192.

Romeo RD, Lee SJ \& McEwen BS 2004 Differential stress reactivity in intact and ovariectomized prepubertal and adult female rats. Neuroendocrinology $80387-393$.

Sapolsky RM \& Meaney MJ 1986 Maturation of the adrenocortical stress response: neuroendocrine control mechanisms and the stress hyporesponsive period. Brain Research 396 64-76.

Schapiro S 1965 Androgen treatment in early infancy: effect upon adult adrenal cortical response to stress and adrenal and ovarian compensatory hypertrophy. Endocrinology 77 585-587.

Seale JV, Wood SA, Atkinson HC, Bate E, Lightman SL, Ingram CD, Jessop DS \& Harbuz MS 2004a Gonadectomy reverses the sexually diergic patterns of circadian and stress-induced hypothalamic-pituitaryadrenal axis activity in male and female rats. Journal of Neuroendocrinology $16516-524$

Seale JV, Wood SA, Atkinson HC, Harbuz MS \& Lightman SL $2004 b$ Gonadal steroid replacement reverses gonadectomy-induced changes in the corticosterone pulse profile and stress-induced hypothalamic-pituitaryadrenal axis activity of male and female rats. Journal of Neuroendocrinology 16 989-998.

Seale JV, Wood SA, Atkinson HC, Harbuz MS \& Lightman SL 2005 Postnatal masculinization alters the HPA axis phenotype in the adult female rat. Journal of Physiology 563 265-274. 
Shanks N, Windle RJ, Perks PA, Harbuz MS, Jessop DS, Ingram CD \& Lightman SL 2000 Early-life exposure to endotoxin alters hypothalamicpituitary-adrenal function and predisposition to inflammation. PNAS $975645-5650$.

Sisk CL, Richardson HN, Chappell PE \& Levine JE 2001 In vivo gonadotropin-releasing hormone secretion in female rats during peripubertal development and on proestrus. Endocrinology 142 2929-2936.

Swanson HE \& van der Werf Ten Bosch J 1963 Sex differences in growth of rats, and their modification by a single injection of testosterone propionate shortly after birth. Journal of Endocrinology 26 197-207.

Viau V \& Meaney MJ 1991 Variations in the hypothalamic-pituitary-adrenal response to stress during the estrous cycle in the rat. Endocrinology 129 2503-2511.

Viau V \& Meaney MJ 2004 Alpha1 adrenoreceptors mediate the stimulatory effects of oestrogen on stress-related hypothalamic-pituitary-adrenal activity in the female rat. Journal of Neuroendocrinology 16 72-78.

Weiser MJ \& Handa RJ 2009 Estrogen impairs glucocorticoid dependent negative feedback on the hypothalamic-pituitary-adrenal axis via estrogen receptor alpha within the hypothalamus. Neuroscience 159 883-895.
Windle RJ, Wood SA, Lightman SL \& Ingram CD 1998a The pulsatile characteristics of hypothalamo-pituitary-adrenal activity in female Lewis and Fischer 344 rats and its relationship to differential stress responses. Endocrinology 139 4044-4052.

Windle RJ, Wood SA, Shanks N, Lightman SL \& Ingram CD $1998 b$ Ultradian rhythm of basal corticosterone release in the female rat: dynamic interaction with the response to acute stress. Endocrinology $139443-450$.

Yukhananov RY \& Handa RJ 1996 Alterations in kappa opioid receptor mRNA levels in the paraventricular nucleus of the hypothalamus by stress and sex steroids. Neuroreport 7 1690-1694.

Received in final form 18 May 2009

Accepted 26 May 2009

Made available online as an Accepted Preprint

26 May 2009 